This is the penultimate version (September 2018) of a chapter to appear in Oxford Studies in Experimental Philosophy, Vol. 3 (Edited by Tania Lombrozo, Shaun Nichols and Joshua Knobe). Please cite the final, published version if possible.

\title{
False memories and quasi-memories are memories
}

\author{
Vilius Dranseika \\ vilius.dranseika@fsf.vu.lt; www.dranseika.lt \\ Faculty of Social Sciences, Arts and Humanities, Kaunas University of Technology
}

\section{Introduction: the factivity constraint and the strong previous awareness condition}

In this report, I present new data bearing on two constraints that are often taken to be essential features of our ordinary use of 'remembering' and 'having a memory': the factivity constraint and the strong previous awareness condition. ${ }^{1}$ Let me introduce these two constraints in turn.

The factivity constraint. The first constraint on the ordinary use of 'remember' is the socalled factivity constraint. Werning and Cheng write: "It is [...] widely agreed that 'remember' comes with a presupposition of the factivity of the intentional object that the state referred to by 'remember' is directed to." (2017: 8). Put simply, the claim is that one can

\footnotetext{
${ }^{1}$ My discussion in this report is limited to applicability of these two constraints to ascriptions of autobiographic episodic memories.
} 
be truly said to 'remember' some event only if that person originally experienced or observed that event (e.g. Holland 1954; Malcolm 1963; Martin \& Deutscher 1966; Chisholm 1989; Bernecker 2008). Any non-factive use of 'remember' then is said to be a mistaken or figurative attribution of memory.

There are some dissenting voices, however. For example, Hazlett claims that non-factive “uses of 'knows', 'learns', 'remembers', and 'realizes' are unexceptional, and do not strike ordinary people as deviant" (2010: 501) while de Brigard argues that

Perhaps the most obvious argument against the factivity constraint is the simple fact that competent speakers just don't abide by it when they use the word 'remembering' $[\ldots]$ The distinction between seeming to remember and actually remembering only makes sense from the point of view of epistemology, but this is because the philosopher has already confined her notion of remembering to veridical memories - a decision that isn't grounded in the way competent speakers use the word 'remembering'. (2017: 130-131)

The strong previous awareness condition - the second constraint discussed in this report states that remembering presupposes identity between the person who remembers an event and the person who originally experienced that event.

In the present form and under the present label, this constraint was articulated by Sydney Shoemaker in his discussion of quasi-memories, in his 1970 paper Persons and their pasts: Quasi-remembering, as I shall use the term, includes remembering as a special case. One way of characterizing the difference between quasiremembering and remembering is by saying that the former is subject to a weaker previous awareness condition than the latter. Whereas someone's claim to remember a past event implies that he himself was aware of the 
event at the time of its occurrence [i.e. remembering is subject to the strong previous awareness condition - V.D.], the claim to quasi-remember a past event implies only that someone or other was aware of it. (271).

Shoemaker's goal in introducing the notion of quasi-remembering - as well as Derek Parfit's, who later adopted this term in his book Reasons and Persons (1984) - was to answer one of the most influential arguments against the memory criterion of personal identity. This argument - mostly associated with Joseph Butler - claims that it is not possible to analyze personal identity in terms of autobiographical memory, for the latter presupposes the former. The notion of quasi-memory was designed to provide a criterion of personal identity that both preserves the spirit of the memory criterion and avoids the circularity charge, since quasimemory does not presuppose that the person who quasi-remembers an event is the same person as the one who originally experienced that event.

Thus understood, remembering is a species of quasi-remembering - all memories are quasimemories, but not all quasi-memories are memories. As described by Parfit, "ordinary memories are a sub-class of quasi-memories. They are quasi-memories of our own past experiences." (1984: 219). ${ }^{2}$ With these definitions, according to Shoemaker, it is possible to "defend the spirit of the claim that memory is a criterion of personal identity" (1970: 281) by rewriting memory criterion as a quasi-memory criterion.

Shoemaker hints at the possibility, however, that the ordinary sense of 'remember' is not bound by the strong previous awareness condition. In discussing this possibility, he introduces two senses of 'remember' - 'remember ${ }_{s}$ ' for a strong sense of remembering that presupposes the strong previous awareness condition and 'remember ${ }_{\mathrm{w}}$ ' for a weak sense of

\footnotetext{
${ }^{2}$ For similar purposes, Penelhum (1967) introduces a different term 'retrocognition', where retrocognition and memory constitute disjoined classes - no memory is retrocognition and no retrocognition is memory. Otherwise retrocognition does not differ from quasi-memories.
} 
remembering, quasi-remembering being one version of weak remembering. Shoemaker then writes: "In the actual world, people remember whatever they remember $_{\mathrm{w}}$, and this makes it difficult to settle the question of whether it is the weak or the strong sense of "remember" that is employed in ordinary discourse." (ibid.) Shoemaker then claims that if "in its ordinary use 'remember' means 'remember ${ }_{\mathrm{w}}$ "', then this would allow to defend not only the spirit but also the letter of the claim that memory is a criterion of personal identity (ibid.).

There is a link between the strong previous awareness condition and the factivity constraint. Violation of the strong previous awareness condition constitutes a partial violation of the factivity constraint - "veridical quasi-memory" (Shoemaker 1970: 273) or "accurate quasimemory" (Parfit 1984: 219) preserves factivity concerning the quasi-remembered event and violates factivity concerning who was the subject of the original experience.

In the present report, I discuss the results of a set of four studies conducted with Lithuanian participants, which collectively suggest that indeed the ordinary use of 'remember' and 'having a memory of' is not bound by either the factivity constraint or the strong previous awareness condition. To the best of my knowledge, this is the first attempt to address empirically the question whether these two constraints are features of our ordinary concept of memory.

\section{Study 1. Quasi-memories and artificial memories}

Study 1 was designed to check whether study participants will consider cases of quasiremembering and cases of artificial memories as cases of remembering. If they do, this would constitute a violation of the factivity constraint (in case of artificial memory) and the strong previous awareness condition (in case of quasi-memory). 
Participants. 291 undergraduate students at a Lithuanian university (78\% females, 20\% males, $2 \%$ chose 'other / prefer not to answer'; mean age: 20.0 ; age $\mathrm{SD}=2.85$; age range 18-51) took part in this pen-and-paper study.

Materials. Three vignettes were constructed and presented in a between-subjects design: quasi-memory (referred as Q in the vignette below), artificial memory (A), and true memory (T) as a control condition. Differences between vignettes are presented in brackets. Original materials in Lithuanian language for all studies reported in this report can be obtained from the author.

Imagine that it is now the year 2086 and scientists have invented a technology that allows one [to install human memories (for Q and T) / to create artificial memories and to install such memories (for A)] into biological storage devices created for this purpose. This technology also allows one to transfer such memories into the brains of other people. A person, into whose brain such [other people's (for Q and T) / artificial (for A)] memories are transferred, cannot distinguish such transferred memories from their own memories. Also, no available technologies can distinguish such memories from others. This technology at the moment is experimental and secret, but it is already sometimes used as an educational tool, since it provides an easy way to transfer knowledge that was memorized by another person. It is also sometimes used as a means to improve psychological wellbeing by transferring pleasant [memories of other people (for Q and T) / artificial memories (for A)]. 
Imagine that Albertas is a teenager who had a lot of [other people's (for Q and T) / artificial (for A)] memories transferred into his brain in his childhood. Albertas does not know and has no reason whatsoever to suspect that such memory transfer was performed on him. [Not all his memories, however, are transferred memories of other people. Some of his memories are from the period before memory transfer. (only in T)] One of [the transferred (for Q and A) / such original (for T)] memories is about tasting rowan-berries in childhood. When someone asks Albertas whether he has ever tasted rowan-berries, Albertas replies with confidence: "Yes, I clearly remember eating rowan-berries when I was a child."

After reading the vignette, participants were asked to answer two questions about memory and knowledge on a six-point Likert scale, anchored at 1 (Completely disagree) and 6 (Completely agree). The first question was "Do you agree that Albertas remembers that he has tasted rowan-berries when he was a child?" and the second one reads 'knows' instead of 'remembers'.

Results. Results of the present study are presented in Figure 1.

Remembers probes. In all three scenarios - quasi-memory, artificial memory, and true memory, one-sample t-tests indicated that participants' agreement that Albertas remembers that he has tasted rowan-berries when he was a child was above the middle-point of the scale: for quasi-memory $(\mathrm{M}=4.87, \mathrm{SD}=1.72, \mathrm{t}(96)=7.83, \mathrm{p}<.001, \mathrm{~d}=0.795)$; for artificial memory $(\mathrm{M}=4.70, \mathrm{SD}=1.87, \mathrm{t}(95)=6.28, \mathrm{p}<.001, \mathrm{~d}=0.641)$; and for true memory $(\mathrm{M}=$ $5.19, \mathrm{SD}=1.37, \mathrm{t}(97)=12.2, \mathrm{p}<.001, \mathrm{~d}=1.23)$.

For knowledge probes, quasi-memories were not considered to be the basis for knowledge. One-sample t-test indicated that participants' agreement that Albertas knows that he has 
tasted rowan-berries when he was a child was below the middle-point of the scale in the quasi-memory scenario $(\mathrm{M}=3.08, \mathrm{SD}=1.95, \mathrm{t}(96)=7.83, \mathrm{p}=.037, \mathrm{~d}=0.215)$. Responses were no different from the midpoint of the scale in other two cases: for artificial memory (M $=3.27, \mathrm{SD}=2.10, \mathrm{t}(95)=1.07, \mathrm{p}=.287, \mathrm{~d}=0.109)$; and for true memory $(\mathrm{M}=3.61, \mathrm{SD}=$ $1.84, \mathrm{t}(97)=0.605, \mathrm{p}=.547, \mathrm{~d}=0.061)$

In all three cases, paired-sample t-tests indicated that scores on 'remembers' scale were higher than on 'knows' scale: for quasi-memory $(\mathrm{M}=4.87, \mathrm{SD}=1.72$ versus $\mathrm{M}=3.08, \mathrm{SD}=$ $1.95, \mathrm{t}(96)=7.83, \mathrm{p}<.001, \mathrm{~d}=0.579)$; for artificial memory $(\mathrm{M}=4.70, \mathrm{SD}=1.87$ versus $\mathrm{M}$ $=3.27, \mathrm{SD}=2.10, \mathrm{t}(95)=4.08, \mathrm{p}<.001, \mathrm{~d}=0.417)$; and for true memory $(\mathrm{M}=5.19, \mathrm{SD}=$ 1.37 versus $\mathrm{M}=3.61, \mathrm{SD}=1.84, \mathrm{t}(97)=6.54, \mathrm{p}<.001, \mathrm{~d}=0.661)$.

Independent-sample t-tests indicated that scores on the 'remembers' scale did not differ for quasi-memories $(\mathrm{M}=4.87, \mathrm{SD}=1.72)$ and artificial memories $(\mathrm{M}=4.70, \mathrm{SD}=1.87), \mathrm{t}(191)$ $=0.65, \mathrm{p}=.516, \mathrm{~d}=0.094$. Also, an independent-sample t-test indicated that scores on the 'remembers' scale did not differ for quasi-memories and true memories $(\mathrm{M}=5.19, \mathrm{SD}=$ 1.37), $\mathrm{t}(183)=1.47, \mathrm{p}=.143, \mathrm{~d}=0.211$. Levene's test indicated unequal variances $(\mathrm{F}=8.88$, $p=.003$ ), so degrees of freedom were adjusted from 193 to 183. Also, an independentsample t-test indicated that scores on the 'remembers' scale were lower for artificial memories than for true memories, $\mathrm{t}(174)=2.10, \mathrm{p}=.037, \mathrm{~d}=0.303$. Levene's test indicated unequal variances $(\mathrm{F}=16.91, \mathrm{p}<.001)$, so degrees of freedom were adjusted from 192 to 174. 
6

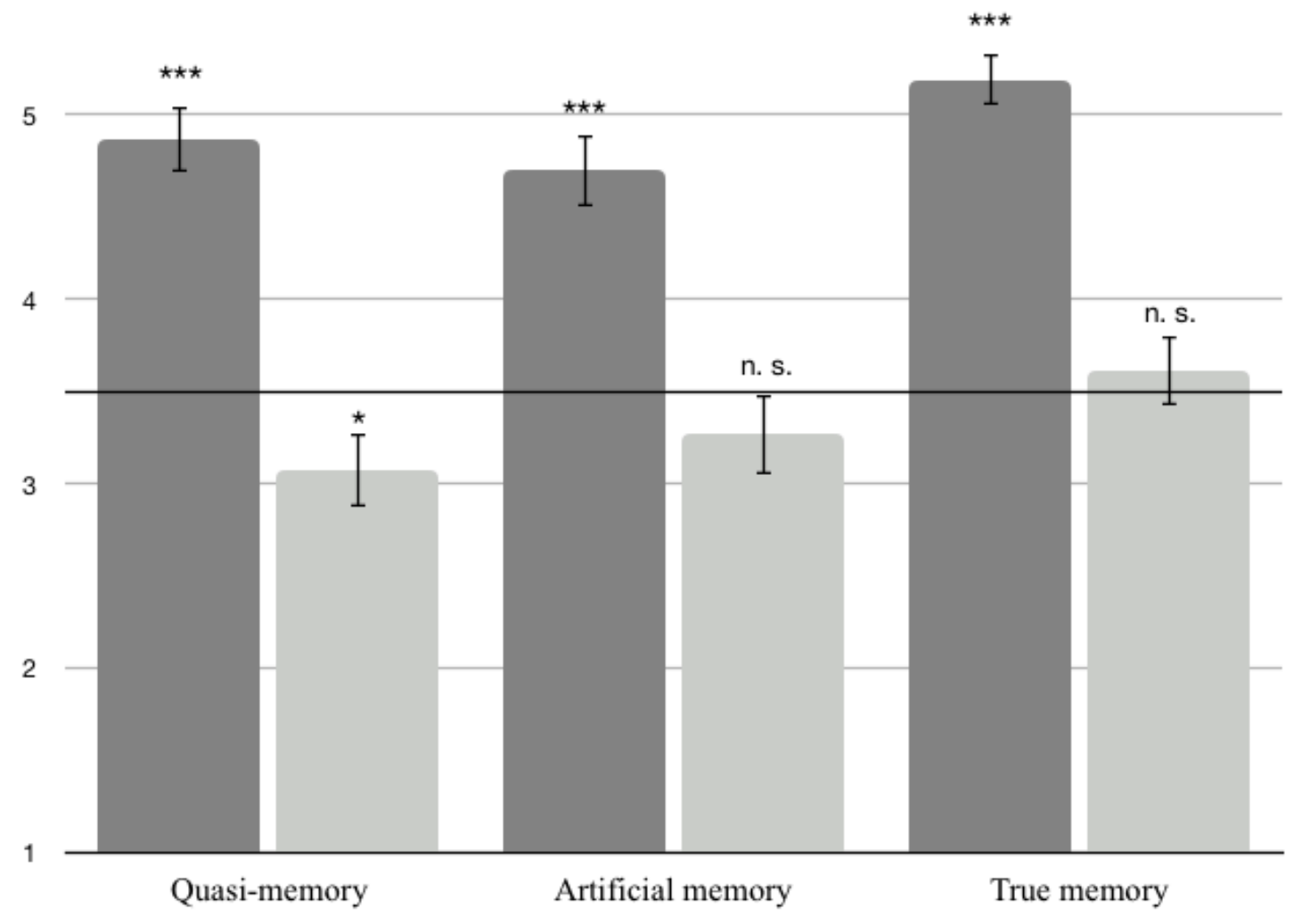

Figure 1. Agreement of participants with whether the agent remembers and knows that he has tasted rowan-berries when he was a child. The black horizontal line indicates the middle of the scale (3.5). Error bars represent standard errors.

Discussion. The main result of Study 1 is that study participants were willing to say that the agent 'remembers' both in case of artificial memory (violating the factivity constraint) and of quasi-memory (violating the strong previous awareness condition).

\section{Study 2. Dream memories}

One limitation of Study 1 is that it employs unusual science fiction scenarios. In the present study I attempted to use a much more mundane scenario of misidentified dream resulting in a 
false memory. Unfortunately, it is not possible to come up with mundane scenarios to test the strong previous awareness condition, so Study 2 is limited to testing the factivity constraint. Participants. 203 online participants took part in a study (60\% females, 37\% males, 3\% chose "prefer not to answer / other"; mean age: 30.4; age $\mathrm{SD}=7.42$; age range 18-60). Participants for this study (as well as for studies 3 and 4) were recruited via advertisements on several Lithuanian popular science Facebook pages.

Materials. Three versions of a vignette were used that varied how much time has passed since the misidentified dream that resulted in a false memory. This was done in order to see whether participants will be more likely to say that the agent 'has a memory' in case of older false memories, the idea being that older false memories will be perceived as integrated into the agent's mental economy to a larger extent. The vignettes read as follows:

Six months ago [ten years ago; yesterday] Ona was attending Algis' twentieth birthday party. Thinking of that party, Ona has a vivid image in her mind of Regina inadvertently spilling red wine all over Jonas, followed by an image of Regina's horrified expression at the mishap, and of Jonas sitting on the grass by the drinks table, completely drenched.

However, no such event in fact occurred during Algis' birthday party. Instead, what happened was just that Ona, very excited about the party, on the same night had a dream of Jonas having wine spilled all over him, and she came to believe that this event occurred, not in her dream, but in reality.

When today a friend asked Ona whether she attended Algis' twentieth birthday party six months ago [ten years ago; yesterday], Ona replied: "Yes, I attended Algis' 
twentieth birthday party. Jonas was also there. I remember him having wine spilled all over him." ${ }^{3}$

After reading the vignette, participants were asked to indicate their agreement with the claim "Ona has a memory of Jonas having wine spilled all over him during a party" on a sevenpoint Likert scale, anchored at 1 (Completely disagree) and 7 (Completely agree). Results

Independent-sample t-tests indicated that scores on 'has a memory of' scale did not differ between groups: yesterday $(\mathrm{M}=4.91, \mathrm{SD}=2.26)$ versus six months $(\mathrm{M}=5.16, \mathrm{SD}=2.23)$ : $\mathrm{t}(135)=.643, \mathrm{p}=.521, \mathrm{~d}=.110$; yesterday versus ten years $(\mathrm{M}=4.82, \mathrm{SD}=2.20): \mathrm{t}(131)=$ $.239, \mathrm{p}=.812, \mathrm{~d}=.041$; and six months versus ten years: $\mathrm{t}(134)=.892, \mathrm{p}=.374, \mathrm{~d}=.153$. Thus participants were pooled for the subsequent analysis.

One-sample t-test indicated that participants' agreement with a claim “Ona has a memory of Jonas having wine spilled all over him during a party" was above the middle-point of the scale: $\mathrm{M}=4.97, \mathrm{SD}=2.22, \mathrm{t}(202)=6.19, \mathrm{p}<.001, \mathrm{~d}=0.434$. In fact, 7 (Completely agree) was a modal answer, covering $38 \%$ of cases.

Discussion. Study 2 looked at the factivity constraint using a more mundane scenario. Participants tended to agree that misidentified dreams were memories (in violation of the factivity constraint). However, no support was found for the claim that the older is the misidentified dream, the more likely it is to be considered a case of memory.

\section{Study 3. Memories and experiences}

One potential issue with the previous studies is that participants may be answering that implanted memories in an individual are memories because her experience of remembering is

\footnotetext{
${ }^{3}$ This vignette is loosely based on a vignette developed by Philipp Rau.
} 
tantamount to the experience of remembering in a person with no implanted memories. And if people mean the experience of remembering rather than a memory (independent of its phenomenological profile), then the view that memory is factive or assumes a previous awareness condition is not refuted. ${ }^{4}$ Study 3 was designed to look into this possibility by giving participants a choice to indicate that what is described it is not a case of having a memory of an event but a case of having an experience of a sort that would be experienced by someone who indeed has a memory of such an event.

Participants. 252 online participants took part in a study (65\% females, 32\% males, 3\% chose "prefer not to answer / other"; mean age: 31.2; age SD = 8.22; age range 18-56). Materials. For the present study, Quasi-memory and Artificial memory vignettes from Study 1 and Ona's dream ('six months ago' version) vignette from Study 2 were used. After reading Quasi-memory and Artificial memory vignettes, participants were asked to make the following choice:

Which of the following two descriptions is more suitable to describe this situation?

1. Even though Albertas hadn't tasted rowan-berries when he was a child, he has a memory of tasting rowan-berries.

2. Albertas does not have a memory of tasting rowan-berries. He simply has an experience like the experience of someone who has such memory.

Participants who received Ona's dream vignette were separated into two groups. The two groups received the task with slightly different wording. Namely, two different synonymous Lithuanian words for 'experience' were used: 'patiria' for one group (Dream memory 1; the

\footnotetext{
${ }^{4}$ I would like to thank one of the reviewers for raising this issue.
} 
same word was used in Quasi-memory and Artificial memory tasks) and 'išgyvena' for another one (Dream memory 2). The task read (with different Lithuanian words for 'experiencing' for different conditions):

Which of the following two descriptions is more suitable to describe this situation?

1. Ona has a memory of Jonas having wine spilled all over him during a party, even though no such event in fact happened.

2. Ona does not have a memory of Jonas having wine spilled all over him during a party. She simply has an experience like the experience of someone who has a memory of such event.

As a result, there were four conditions (Quasi-memory, Artificial memory, and two variations of Ona's dream), presented in between-subjects manner.

Results. A chi-square test of goodness-of-fit was performed to determine whether the two options were equally preferred. In all four conditions, significantly more participants chose 'has a memory' answer. Quasi-memories: $X^{2}(1, N=66)=11.9, p<.001 .71 \%$ of participants chose 'has a memory' answer. Artificial memories: $X^{2}(1, N=60)=19.3, p<.001 .78 \%$ of participants chose 'has a memory' answer. Dream memory 1: $X^{2}(1, N=63)=7.0, p=.008$. $67 \%$ of participants chose 'has a memory' answer. Dream memory 2 results were exactly identical to results in Dream memory 1: $X^{2}(1, N=63)=7.0, p=.008 .67 \%$ of participants chose 'has a memory' answer. Results of Study 3 are presented in Figure 2. Independent sample chi-square tests of association were performed to determine whether the response patterns to the four conditions differed. No differences between groups were observed, $X^{2}(3, N=252)=2.68, p=.443$. After pooling across conditions, a chi-square test 
of goodness-of-fit was performed to determine whether the two options were equally preferred. Answers were not equally distributed in the population, $X^{2}(1, N=252)=42.9, p<$ .001 . Across all four conditions, $71 \%$ of participants chose 'has a memory' answer.

\section{Percent of 'has a memory' answers}

$100 \%$

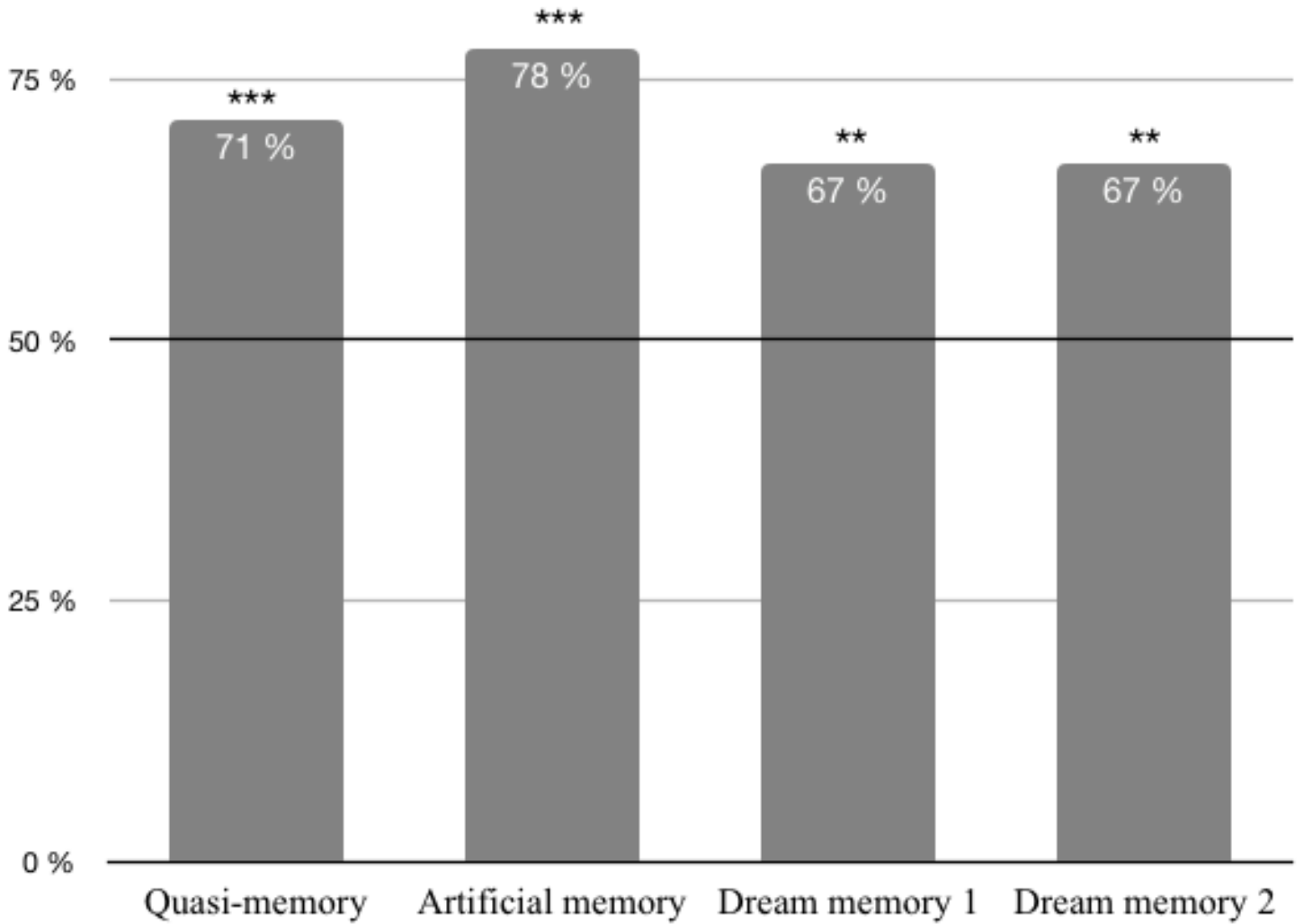

Figure 2. Percent of participants who chose 'has a memory' answer. The black horizontal line indicates proportion of the answers that could be expected to obtain by chance alone $(50 \%)$.

Discussion. In all four conditions, participants were more likely to choose an option ascribing a memory of an event than an option ascribing only an experience of having a memory. 


\section{Study 4. Memories, money, and guns}

Study 4 was designed to look into another potential objection - namely, that non-factive memories are not memories in the same way as false money is not money or a false gun is not a gun.

To this effect, Cheng and Werning write:

In psychology, the adjective-noun combination "false memory" is often used to refer to a false mnemonic representation. The use of this phrase by psychologists is sometimes interpreted as if memory in psychology would not be regarded as factive. However, this conclusion would be justified only if "false" were an intersective adjective, for which the inference from " $\mathrm{x}$ is AN" to " $\mathrm{x}$ is $\mathrm{N}$ " is valid. The more plausible interpretation, we think, is that "false" in "false memory" is a privative adjective like "false" in "false money" or "fake" in "fake gun". For privative adjectives, the inference is not valid: false money is not money, a fake gun is not a gun and, likewise, false memory is not a case of memory. (1351, note 1$)$

I decided to run a study to look into this.

Participants. 455 online participants took part in a study (63\% females, 34\% males, 3\% chose "prefer not to answer / other"; mean age: 30.8; age SD = 7.88; age range 18-60). All participants who took part in either Study 2 or Study 3 (no participants overlap between studies 2 and 3) also took part in Study 4. Study 4 was presented on a separate page and participants were not allowed to return to the previous study.

Materials. Participants were asked to indicate on the seven-point Likert scale (anchored at 1 (Completely disagree) and 7 (Completely agree)) the extent to which they agree or disagree with each of the following three claims: 
A false memory is still a memory.

A fake - toy - gun is still a gun. ${ }^{5}$

False money is still money.

Results. One-sample t-tests were conducted for all three scenarios - memory, gun, and money. In the case of memory, the mean agreement was above the middle-point of the scale: $(\mathrm{M}=4.47, \mathrm{SD}=2.08, \mathrm{t}(454)=4.83, \mathrm{p}<.001, \mathrm{~d}=0.226)$. In the case of gun, mean agreement did not differ from the middle-point of the scale: $(\mathrm{M}=3.96, \mathrm{SD}=2.17, \mathrm{t}(454)=0.39, \mathrm{p}=$ $.697, \mathrm{~d}=0.018)$. While in the case of money, mean agreement was below the middle-point of the scale: $(\mathrm{M}=2.96, \mathrm{SD}=2.07, \mathrm{t}(454)=10.71, \mathrm{p}<.001, \mathrm{~d}=0.502)$.

Paired-samples t-tests indicated that scores for 'memory' were higher than for 'gun': $\mathrm{t}(454)=$ 4.73, $\mathrm{p}<.001, \mathrm{~d}=0.222$ ) and 'money': $\mathrm{t}(454)=14.1, \mathrm{p}<.001, \mathrm{~d}=0.659)$.

Modal answer was 7 (Completely agree) for memories (selected by $22 \%$ of participants) and 1 (Completely disagree) for guns (20\%) and money (38\%).

Discussion. In previous studies, I found that recalling other people's memories or artificial memories is considered to be 'remembering' or 'having a memory'. This additional brief study suggests that, contrary to what Cheng and Werning suggested, study participants were willing to agree that false memories are memories. This is in line with other studies reported in this report, where participants were willing to say that the agent remembers in situations where factivity constraint on memory was violated. However, one limitation of Study 4 is that - in contrast to Studies 1, 2, and 3 - the study was conducted on study participants who already had taken part in another study on memory.

\footnotetext{
${ }^{5}$ The word 'toy' was added to the statement about the gun because otherwise 'fake gun' in Lithuanian language would likely be interpreted as 'an exact copy of a given gun' (e.g. a counterfeit but indistinguishable from the original and fully functional copy of an old gun produced in order to sell it to a gullible guns collector).
} 


\section{General discussion}

The present set of studies suggests that the factivity constraint and the strong previous awareness condition are not essential features of our ordinary use of 'remembering' and 'having a memory of'. Concerning the factivity constraint, artificial memory and misidentified dream memory vignettes involve violations of factivity, and in all these cases study participants tended to agree that the agent 'remembers' (Study 1) or 'has a memory' (Studies 2 and 3). The fact that study participants tended to agree that the agent 'remembers' (Study 1) and 'has a memory' (Study 3; Quasi-memory condition) in cases of having implanted other people's memories, suggests that the ordinary notion of memory is not bound by the strong previous awareness condition either.

These findings, of course, should be taken as only the first preliminary and very limited step in the direction of better understanding of constraints that rule our ordinary notion of remembering. Among limitations of this study, I would like to stress the very limited set of experimental vignettes used, the fact that it is unclear whether the results would generalize to other languages than Lithuanian, as well as that some of the vignettes were based on science fiction scenarios.

In summary, the data provided in this report provide some evidence to motivate skepticism concerning whether the factivity constraint and the strong previous awareness condition are essential features of our ordinary use of 'remember'.

There is also an intriguing possibility that the uses of 'remember' documented in this report reflect a relatively recent conceptual development that can perhaps be associated with exposure to such ideas in pop culture. The present methods are not suitable to address this question and one would rather need to use historical linguistic corpora to see whether they contain examples of non-factive uses of 'remembers' or 'has a memory of'. 
Acknowledgements: I would like to thank Phillip Rau, Vytautas Valatka, and two anonymous reviewers for valuable suggestions and Phyllis Zych Budka for proofreading the manuscript.

\section{References}

Bernecker, S. (2008). The Metaphysics of Memory. Dordrecht: Springer.

Cheng, S., and Werning, M. (2016). What is episodic memory if it is a natural kind? Synthese, 193(5): 1345-85.

Chisholm, R. M. (1989). Theory of Knowledge, 3rd edition, Englewood Cliffs, NJ: Prentice-Hall.

De Brigard, F. (2011). Reconstructing memory. The University of North Carolina at Chapel Hill.

De Brigard, F. (2017). Memory and Imagination. In Bernecker, S., \& Michaelian, K. (Eds.). (2017). The Routledge Handbook of Philosophy of Memory. Routledge, pp. 127-40.

Hazlett, A. (2010). The myth of factive verbs. Philosophy and phenomenological research, $80(3), 497-522$.

Holland, R.F. (1954). The Empiricist Theory of Memory. Mind, 63(252): 464-86.

Malcolm, N. (1963). Knowledge and Certainty, Ithaca, NY: Cornell University Press.

Martin, C.B. and Deutscher, M. (1966). Remembering. Philosophical Review, 75(2): 161-96.

Parfit, D. (1984). Reasons and Persons, Oxford: Oxford University Press.

Penelhum, T. (1967). 'Personal identity', in The Encyclopedia of Philosophy (Volume 6), P. Edwards (ed.), New York: Macmillan, pp. 95-107.

Shoemaker, S. (1970) Persons and their pasts. American Philosophical Quarterly, 7(4): 26985. 
Werning, M., \& Cheng, S. (2017). Taxonomy and unity of memory. In Bernecker, S., \& Michaelian, K. (Eds.). (2017). The Routledge Handbook of Philosophy of Memory. Routledge, pp. 7-20. 